\title{
Knowledge and Opinion about the same thing in APo A-33
}

Lucas Angioni

angioni.lucas@gmail.com

Universidade Estadual de Campinas (UNICAMP), Campinas, Brasil

resumo Procuro mostrar que o contraste que Aristóteles oferece entre conhecimento demonstrativo e opinião, em Segundos Analíticos I-33, não faz parte de nenhum projeto epistemológico geral e, na medida em que toma apenas opiniões explanatórias para comparação, pressupõe fortemente traços importantes da demonstração científica, tal como expostos nos capítulos anteriores do livro I dos Segundos Analíticos. Aristóteles está interessado no contraste entre opinião e conhecimento apenas do ponto de vista da relevância explanatória. As noções modais que aparentemente são invocadas para dar conta da distinção entre opinião e conhecimento também dizem respeito tão somente à relevância explanatória.

palavras-chave essencialismo; explicação; causalidade; silogismo; epistemologia; necessidade

\section{1.}

At some point in Posterior Analytics A-33, Aristotle raises two questions. The text runs as follows: "how is it possible to opine and have knowledge of the same thing? And why will opinion not be knowledge if you admit that you can opine everything that you know?"1 (89a11-3).

There are two explicit questions in this passage:

(Q1) is it possible to have opinion and knowledge about the same object or the same thing?

(Q2) if one admits that it is possible to have an opinion about the object one knows, why opinion does not collapse into knowledge? 
These questions are not exactly the same as the question addressed at the beginning of the chapter. One thing is to ask whether knowledge and opinion are the same cognitive state (or to ask whether the object of knowledge is the same as the object of opinion, 88b30-1), but it is a different issue to ask whether it is possible to have opinion and knowledge about the same object. Of course, if knowledge and opinion are the same cognitive state, it follows that one always has opinion and knowledge about the same object. But if knowledge and opinion are not the same cognitive state, it is still possible for someone to have opinion and knowledge about the same object.

I have argued elsewhere that Aristotle is not concerned in this chapter with a general epistemological distinction between knowledge and opinion. ${ }^{2}$ One might trace back how Aristotle would deal with a distinction like this, but a general approach to it is not Aristotle's interest at this point. He focuses here on a more particular distinction between, on the one hand, what he has been describing in Posterior Analytics as scientific knowledge or demonstrative knowledge and, on the other hand, a specific kind of beliefs or opinions that might reasonably claim to be equivalent to scientific knowledge. ${ }^{3}$ Both items in this comparison (that is, scientific knowledge and this specific sort of opinion) share a common feature: both are cast as explanations. ${ }^{4}$

From the beginning of the chapter to $89 \mathrm{a} 10$, the questions were (i) whether knowledge and opinion are different from each other and (ii) whether the object of knowledge and the object of opinion are different from each other. The core of Aristotle's discussion was to argue that the object of knowledge is "universal and necessary" (88b31-2) whereas the object of opinion lacks the proper kind of universality and necessity. Now, the universality and the necessity Aristotle relies on in this context can only be understood in the triadic framework of explanations and, most precisely, of syllogistic explanations. ${ }^{5}$ Aristotle grounds the difference between knowledge and opinion on differences between the middle terms respectively given as explanatory factors for a given conclusion. Whereas knowledge is an explanation through a middle term that is "universal" in the sense advanced at 73b26-7 as well as "necessary" in the sense of being the primary cause that cannot be replaced by any other for a fully appropriate explanation of its explanandum, ${ }^{6}$ opinion is an explanation 
"through a premise that is immediate but not necessary" (89a4), i.e., an explanation through a middle term which presumably is not universal in the sense advanced at 73b26-7 nor "necessary" in the sense of being the primary cause.

At 89a11-3, Aristotle is concerned with a similar comparison. This is clear from his next lines, in which he describes some assumptions underlying the questions he has just formulated. The text runs as follows: "A knower and an opiner would follow the same path through the middle terms until they come to the immediates. Hence, since the former knows, the opiner knows too. Of course, just as you can opine the fact, so too can you opine the reason why, and this is middle term"7 (89a13-6).

His first step (89a13-15) tries to give some plausibility for the antecedent in question (Q2): a knower and an opiner might accompany each other in a chain of reasoning through middle terms, until they reach the immediate terms in which the chain stops. One might wonder how knowledge and opinion could be distinguished from each other in such a situation. I will address this question later. First, I stress that, in his second step (89a15-16), Aristotle makes it clear that the middle terms in question are answers to the why-question, so that the opinions at stake are opinions involving an explanation. Thus, an important assumption underlying both questions is that one can have opinions not only that but also why: not only about elementary propositions in predicative form, but also about explanations formulated in the triadic syllogistic framework. ${ }^{8}$ Therefore, the "objects" Aristotle is comparing, the "knowable" and the "opinable", have both the same form (in this context):

that $C$ is $A$ because of its being $B .{ }^{9}$

As soon as these assumptions are clear, Aristotle develops his answers for $(\mathrm{Q} 1)$ and $(\mathrm{Q} 2)$. The core of his solution will rest on a basic distinction (89a28-29) and on analogies (89a24-25, 29-33). The basic distinction is that "the same" is said in many ways: there can be opinion and knowledge of the same thing according to one of these ways, but not according to others. And the main analogy is the following: as there can be true and false opinion of the same thing, similarly there can be knowledge and opinion of the same thing. However, before the analogy is set up, there is a very challenging passage, in which Aristotle seems to suggest his answers is a rather allusive way. One of my claims in this paper is that, in order 
to understand not only this obscure passage but also the true-and-falseopinion analogy, we must consider seriously the assumption highlighted above: when Aristotle compares scientific knowledge and opinion, he is talking about two sorts of explanations which are cast in a syllogistic frame.

First figure syllogisms (or, even more particularly, Barbara syllogisms) are the relevant syllogistic framework at this point. I need not discuss here what is the role Aristotle has ascribed to syllogistics in his theory of demonstration. ${ }^{10}$ All I need is to stress that the triadic structure of first figure syllogisms is used by Aristotle as a good tool to catch and express explanatory or causal relations. The explanandum is expressed as a predicative relation between major and minor term: what one needs to explain is why a given $C$-term has the property introduced by the $A$-term. The explanation is cast in the form of relations each extreme has with the middle term, $B$ : the $B$-term introduces a more basic property attributed to the $C$-term, and this more basic property not only entails but also grounds the property introduced by the $A$-term. ${ }^{11}$

With this framework in mind, it is easy to realize that someone might have scientific knowledge about the fact that $C$ is $A$ whereas another person has only a doxastic explanation (or an explanatory opinion) about the same fact that $C$ is $A$. The difference between opinion and knowledge will rest, then, on the middle terms one picks up as explaining the fact that $C$ is $A .^{13}$

I will try to show that this is the way in which the analogy with trueand-false opinion and the distinction between uses of "the same" work for the solution of questions (Q1) and (Q2). I will start with a discussion of the passage 89a23-37, in which Aristotle expounds his solution. Then, I will come back to the challenging passage 89a16-23. I will try to show that the syllogistic-explanatory framework allows us a better understanding of Aristotle's argument in harmony not only with what he has said in the first part of this chapter, but also with other difficult passages from Posterior Analytics A-13 and A-6. Then, I will focus on some hard philological issues concerning the awkward terminology used in 89a33-7. Finally, I will try to show that Aristotle's concluding remarks, at 89a38-b6, make perfectly good sense and are coherent with what he has said previously in the chapter. 
Aristotle advances a positive answer to question (Q1): "Now, it is not in every sense that there is opinion and knowledge of the same thing, but just as there can be both false and true opinion of the same thing, so there can be both knowledge and opinion of the same thing"14 (89a23-25).

This answer rests on an analogy: as the same thing is liable to true as well as to false opinion in some way, so the same thing is liable to opinion as well as to knowledge in some way. This solution depends on the reference of "the same thing" ("tou autou") in 89a23, 24, 25. Thus, Aristotle's next step is to argue that "the same thing" is said in many ways ("to auto pleonachos legetai"): "but since 'the same' is used in several ways, in one way it is possible [sc. to have both knowledge and opinion about the same thing] but in another way it is not possible"15 (89a28-29).

Now, there is no need of distinguishing senses of "identical" or senses of "same" to understand Aristotle's point. His claims are based on the reference-shift of the expression "the same thing" according to context. ${ }^{16}$ Aristotle explains that there can be a true opinion about the diagonal being not-commensurate with the side, as well as there can be a false opinion about the diagonal being commensurate with the side. Of course, each opinion has a different proposition as its object, and in this sense they are not about the same thing. Accordingly, each opinion has a different essence: what it is to be a false opinion about the diagonal being commensurate with the side is different from what it is to be a true opinion about the diagonal being not-commensurate with the side. ${ }^{17}$ Nonetheless, they still can be described as opinions about "the same thing" inasmuch as the diagonal is the same (cf. 89a29-32).

Now, one must be careful with Aristotle's comparison between this case and the knowledge-and-opinion case. There is an analogy between the cases: the relations between false and true opinion is similar to the relation between opinion and knowledge. But such an analysis of his solution is too vague. An analogy is a similarity between two relations that, even being different, have one relevant feature in common. Thus, the fact that an analogy holds between, say, two pairs of relata does not imply that the relation is exactly the same, nor imply that the relata are the same. ${ }^{18}$ In the case of true and false opinion, the situation is the following: 
(1) if C (e.g., the diagonal) is the referent of "the same", there can be true opinion as well as false opinion about the same thing;

(2) but if the predication " $C$ is $A$ " (e.g. "the diagonal is not-commensurate with the side") is the referent of "the same", then a disjunction applies: for each substitution of the pair $C$ - $A$ with concrete terms, the predication will be the object either of true opinion or of false opinion. ${ }^{19}$

It would be wrong to assume that the same situation will mechanically apply to the case of knowledge and opinion. ${ }^{20}$ The first part of the comparison does not offer difficulty, since it is true to say that:

(3) if $C$ (e.g., the diagonal) is the referent of "the same", there can be opinion as well as knowledge about the same thing.

But it would be a complete mistake to say that:

(4) if the predication " $C$ is $A$ " (e.g. "the diagonal is not-commensurate with the side") is the referent of "the same", then a disjunction applies: for each substitution of the pair $C$ - $A$ with concrete terms, the predication will be the object either of opinion or of knowledge.

The mistake is to assume a single predication as the object of opinion and knowledge in this part of the comparison, ${ }^{21}$ while Aristotle is actually focusing on the triadic framework of explanations. The case of knowledge and opinion is similar to, but not exactly identical with, the case of true and false opinion. ${ }^{22}$ First, there is a relevant difference between the two cases in the first option for the reference of "the same thing": it does not matter whether "the same thing" refers to $C$ or to " $C$ is $A$ ". Thus, it is true that:

(3) if $C$ is the referent of "the same", there can be opinion as well as knowledge about the same thing (see 89a36).

But it is also true that:

(3') if " $C$ is $A$ " is the referent of "the same", there can be opinion (and only a true opinion) as well as knowledge about the same thing. ${ }^{23}$

Consequently, the complete story will run thus:

(3") if $C$ or " $C$ is $A$ " is the referent of "the same", there can be opinion (and only true opinion for " $C$ is $A$ ") as well as knowledge about the same thing.

But this is not the most important part of the comparison. The decisive point is that the difference between knowledge and opinion rests on the different middle terms used to explain the same true predication taken as explanandum. Thus, what results from the comparison between this case and the case of true and false opinion must be stated in the following way: 
(5) if the referent of "the same" is " $C$ is $A$ because of $B$ ", ${ }^{24}$ then a disjunction applies: "the same thing" is object either of (true) opinion or of knowledge.

The relevant difference between true opinion and false opinion is given in terms of falsity or truth of basic predications, so that it is enough to consider the predicative statements at stake in order to grasp the difference. Now, the relevant difference between opinion and knowledge is not given in terms of mere falsity or truth of the basic predication " $C$ is $A$ ", nor is it given in terms of modality, nor in terms of epistemological attitude towards the proposition, nor in terms of mode of apprehension. It is rather given in terms of the explanatory factor chosen to explain the explanandum at stake. ${ }^{25}$

This interpretation has a clear advantage in conceptual terms: it is interesting to distinguish between scientific knowledge and opinion in terms of explanatory relevance. Now, this interpretation has also many exegetical advantages. First of all, I can explain in a better way why Aristotle shifts from "animal" (89a34) to "man" (89a36-7) as the supposed objects of the cognitive states under comparison.

In 89a36-7, Aristotle says that: "The thing [sc. which is the object of both knowledge and opinion] is the same, because it is man, but the way [sc. in which man was taken] is not the same". ${ }^{26}$ He means that the object of knowledge and the object of opinion are somehow the same because "man" is the same. "Man" is the subject of which something is predicated, and this is in accordance with (3"). Thus, there can be knowledge and opinion of "the same thing" if "the same thing" is taken as referring to man. But the way of taking the explanandum ("to d' hos") is not the same in each case. One might argue that "the different ways" in which one takes man merely amounts to different predicates attributed to man. However, since the knowledge at stake is demonstrative knowledge, and since demonstrative knowledge is defined in terms of understanding the primary cause that makes a given subject have a given attribute, it is sound to take man not only as a subject for attributes but also, and most importantly, as the $C$-term for a triadic explanation. Therefore, the different ways of taking man in order to explain one of his attributes amounts exactly to a difference in the middle term selected for the explanation. "Animal" is the middle term through which one attains scientific knowledge of why 
man is (say) able to perceive. On the other hand, one has opinion about why man is able to perceive if one selects a middle term different from animal. ${ }^{27}$ Thus, if "the same thing" is taken as the triplet " $C$ is $A$ because of $B$ ", there cannot be the same object for opinion and knowledge.

Thus, I argue that there are actually two analogical comparisons: one accounting for a positive answer of (Q1), the other accounting for a negative answer of (Q1), as is clear from 89a29. The complete story is the following:

(A) First analogy: as $C$ is to true and false opinion, so $C$ and " $C$ is $A$ " are to knowledge and opinion; the relation here can be described as "being the raw subject-matter", i.e., being that thing about which one believes to grasp something. This analogy involves (1) and (3") above.

(B) Second analogy: as " $C$ is $A$ " is to true and false opinion, so the triplet "C is A because of B" is to knowledge and opinion. The relation here is "being the exact object one grasps". The analogy here involves (2) and (5), not (2) and (4)..$^{28}$

Now, the first analogy (A) is unable to catch the difference between the relata (i.e., between true and false opinion, on the one hand; between knowledge and opinion, on the other), whereas the second analogy (B) allows us to catch the relevant difference between them. In virtue of the alternation rule of analogies, from $(\mathrm{B})$ it follows $(\mathrm{B}$ '): as " $C$ is $A$ " is to the triplet " $C$ is $A$ because of $B$ ", so true and false opinion are to knowledge and opinion. The first two pairs can both be described as "exact objects of cognitive states which are incompatible with each other", and the two remaining pairs can both be described as "cognitive states which are incompatible with each other". In the same way, from (A) it follows (A'): as " $C$ " is to " $C$ " or ' $C$ is $A$ ", so true and false opinion are to knowledge and opinion: the first two pairs can now be described as "raw subject-matter of cognitive states which are somehow compatible with each other", and the two remaining pairs can both be described as "cognitive states which are somehow compatible with each other".

\section{3.}

Now, I have to explain what Aristotle means with what is taken to be an introduction of modal terminology ("me endechesthai me einai", 
89a34). Standard interpretations will be content with a translation like this: "knowledge is of animal in such a way that it is not possible [for man] not to be an animal". I argue that a translation along these lines is not only misleading but also completely wrong. ${ }^{29}$ First of all, "animal" is not just a predicate as if Aristotle's focus were just a basic predication in itself. Neither is "animal" another subject for a new basic predication to be explained, as if Aristotle were unexpectedly shifting his example from "man" to "animal". As I have argued, "animal" is performing the role of middle term in this context. What Aristotle means is that animal is the appropriate middle term that explains in a scientific way why man has such and such a property (say, being able to perceive).$^{30}$ The so called modal terminology does not apply to any predicative tie in itself. What I mean with "predicative tie in itself" is a predication taken in itself with no consideration about its relations with other predications. The so called modal terminology applies to the middle term in the triadic framework of the explanation, but this does not imply that this terminology is applied exactly to predicative ties. It applies to the middle term qua middle term, that is, inasmuch as the middle term is advancing an explanatory claim. This explanatory claim only makes sense if the middle term is taken both as predicate of $\mathrm{C}$ and as subject of (and ground for) $A$ in the triadic framework of explanations. ${ }^{31}$ However, it will be wrong to infer that what I am suggesting would be captured in the standard modalization of predications, as if Aristotle were asking for premises with the form " $\mathrm{NecBaA}$ " and "NecCaB". As will become clearer, this modal interpretation is not enough to catch Aristotle's meaning. Different middle terms can be found which yield true statements when they replace " $B$ " in "NecBaA" and "NecCaB". For instance, "Nec every mammal is able to perceive" and "Nec every man is mammal", as well as "Nec every animal is able to perceive" and "Nec every man is animal". But "mammal" does not perform an explanatory role in the same way as "animal". Now, Aristotle's usage of the expressions "what cannot be otherwise" and "what cannot be another one" in these contexts is meant to catch these differences in explanatory relevance. The expression "what cannot be otherwise" is used to pick up the explanatory factor which is necessary in the sense of being required for a full and ultimate explanation of the explanandum at stake. 
Therefore, the right translation of 89a33-4 is the following:"knowledge is of animal in such a way that it is not possible [sc. for the middle term] not to be animal". Therefore, what seems to be a modal terminology actually turns out to be a requirement for the middle term qua explanatory factor: if, for a given attribute of man (say, being capable of perceiving), there is an appropriate explanation deserving the title of demonstrative knowledge, its middle term cannot be any other, besides the one that captures the appropriate causal factor (say, animal). And the expression "knowledge is of X" $(89 \mathrm{a} 33,34)$ should rather be taken in the sense of "knowledge depends on X [as middle term] as its most important factor", not in the sense of " $\mathrm{X}$ is the thing one comes to know". ${ }^{32}$

Lines 89a35-6 present an even more awkward jargon. I will return to this. Let me first discuss the passage $89 \mathrm{a} 16-23$, in which a solution to the question (Q1) is suggested in a very difficult language with supposed "modal" terminology.

\section{4.}

The first step of the argument runs as follows: "or if you grasps that which cannot be otherwise in this way, as you grasps the definitions through which demonstrations proceed, you will then not have opinion, but knowledge" (89a16-19). ${ }^{33}$

First of all, it is useful to keep in mind that Aristotle frequently introduces his own solution with the particule " $e$ " (usually translated as "or"). This phrasing of his words is far from indicating some precaution or hesitation: it is just a usual stylistic tool which Aristotle uses when the questions at stake, which he just came to expound, rest on wrong assumptions. ${ }^{34}$ In this case, the wrong assumption is that knower and opiner could accompany each other through the same series of middle terms in an explanatory chain. The particule " $e$ " introduces the correction of this wrong assumption.

My interpretation involves many philological details about syntactical difficulties in this passage, but its core rests on the move I have described in the previous section: the expression "that which cannot be otherwise" refers to middle terms - to middle terms that express the primary causes and cannot 
be replaced with any other in a scientific explanation. Thus, middle terms are "necessary" in the sense of being required for a primary explanation. If one grasps such a middle term, one has knowledge, not mere opinion.

The syntax of the text is difficult and editors have bracketed the verb "echei" in 89a18. ${ }^{35}$ Maybe it is not necessary to bracket this verb. Before discussing this point, it is important to realize two options for understanding the syntax of the adverb "houtos":

(a) this adverb can be correlated with "hosper" (89a17), as a translation along the following lines may clarify: "if one grasps that which cannot be otherwise in such a way as one grasps the definitions through which demonstrations proceed". The way in which we grasp definitions will be the touchstone for understanding the way in which we grasp what cannot be otherwise. ${ }^{36}$

(b) this adverb can be taken as prosleptically emphasizing the relevant feature of the complement of the verb ("what cannot be otherwise"), so that the sentence introduced with "hosper" is rather an additional comparative remark. The following translation may illustrate what I mean: "if one grasps that which cannot be otherwise in this way [i.e., as something which cannot be otherwise], in the same manner as one grasps the definitions through which demonstrations proceed [sc., as something which cannot be otherwise]".

The bracketing of "echei" is immaterial to my point. If "echei" is supressed, then "tous horismous" turns to be a second complement of the verb "hypolepsetai" from the previous line. The result might be the following: "if one takes what cannot be otherwise as definitions", i.e., if one believes that what cannot be otherwise are the definitions to be used in demonstrations. Now, I can attain this same result with option (b) above, which keeps "echei" in the text taking it as a cognitive verb (see 93a28) equivalent to "hypolambanein" ("grasp" or "understand"). ${ }^{37}$

My interpretation is compatible with either option (a) or (b). But I have a stronger inclination towards (b). As it will become clearer from the constrast with the opinion case, one has scientific or demonstrative knowledge when one explains why $C$ is $A$ through its primary cause, and this primary cause, which cannot be otherwise in the sense that it cannot be replaced with any other if the explanation is to be appropriately scientific, turns out to be the essence of the explanandum. Insofar as 
essences are expressed in definitions, it is clear that grasping a primary cause as primary - as the middle term that cannot be replaced with another one - involves grasping the definiens account of its explanandum. Aristotle is not suggesting that the way in which we grasp definitions is a touchstone for the way in which we should grasp "what is necessary". $\mathrm{He}$ is rather saying that grasping the necessary middle terms - the middle terms that catch the primary causes - amounts to grasping the essence and the definition of the explanandum.

In short, Aristotle is saying that one will have knowledge when one understands that the middle term at stake is "necessary" for a full explanation of why $C$ is $A$. Claims of knowledge might have this form:

- that $C$ is $A$ because of its being $B$ and it cannot be because of its being $D$ (or anything different from $B$ ); or

- that $C$ is $A$ because of its being $B$ and that this causal relation cannot be otherwise (as the very definitions from which demonstrations proceed cannot be otherwise). ${ }^{38}$

Most of Aristotle's meaning will become clearer from the contrast with opinion, which is introduced with the following words: "on the other hand, if you grasps that these things are true, but not that these things are attributed to them in virtue of their essence or in virtue of their form, you will then have opinion, but not knowledge in the true sense of the word, not only about the fact that but also about the reason why" (89a19-21. My own translation).

I stress again that Aristotle is concerned with objects of opinion with the following form:

- that $C$ is $A$ because of its being $B$.

There are a lot of exegetical questions here. The first one is what the expression "that these things are true" (alethe men einai) in 89a19 is referring to. It may be taken in two ways:

(a) that $C$ is $A$ is true;

(b) that $C$ is $A$ because of its being $B$ is true.

The truth-bearer in (a) is a predication, whereas in (b) it is an explanation with three terms, which can be unpacked into a syllogistic combination of three predications. As for the expression "these being attributed to those things" ("tauta ge autois hyparchein", 89a19-20), it also may be taken in two ways: 
(a') tauta as referring to $A$, whereas autois refers to $C$.

(b') tauta as referring to " $A$ because of $B$ ", whereas autois refers to $C$.

My solution is compatible with either of these options, although I am more inclined to one of them. With (a) and (a'), the basic meaning is that the opiner grasps that the conclusion of his explanation $(C$ is $A$ ) is true, but falls short of grasping that this conclusion is true because the essence or the form of its explanandum is what it is. ${ }^{39}$ The opiner chooses a middle term which does not capture the essence of its explanandum and this amounts to saying that he fails at catching the primary cause of its explanandum.

The basic outcome of such an interpretation is interesting for the contrast between demonstrative knowledge and opinion. But (b) and (b') render an even more interesting option. Actually, (a) and (a') leaves open the possibility that the $B$-term is not truly predicated of $C$, so that what is wrong with the opiner's explanation is that (at least) his minor premise is false. On the other hand, (b) and (b') exclude this possibility. The meaning of $(b)$ is that the opiner has an explanation which is true in the sense that the three predicative ties are themselves true: that $C$ is $A$ is true, that $C$ is $B$ is true, and that $B$ is $A$ is true. ${ }^{40}$ However, ( $\left.\mathrm{b}^{\prime}\right)$ remarks that $A$-grounded$b y-B$ (which is picked up with "tauta") does not hold of $C$ according to its essence or form. The essence in question might seem to be the essence of the $C$-term, but I argue that it is rather the essence of the $A$-term or the essence of the explanandum ( $A$ as attributed to $C) .{ }^{41}$ I will argue more for this claim in a while. First, let me stress that (b') would be saying that, in the opiner's explanation, even if being $B$ gives some ground for being $A$, being $B$ is not the primary ground for being $A$ and is not the essence of being $A$ : the point is that $C$ is $A$ might (and should) be better explained through another feature of $C$ 's different from being $B$. In other words, even if being $A$ can be somehow explained through being $B$, being $A$ is not fully or primarily explained through being $B$. This makes the opiner's $B$-term falls short of being "the necessary one".

Take the contrast between the following explanatory syllogisms:

Syllogism 1:

Every mammal is able to perceive

Every man is mammal

Every man is able to perceive 
Syllogism 2:

Every animal is able to perceive

Every man is animal

Every man is able to perceive

In syllogism 1, all predications are themselves true. Probably they are also necessarily true in Aristotle's eyes. And being a mammal gives at least some reasonable explanation of why every man is able to perceive. But being a mammal does not catch the primary cause that makes man able to perceive. And although it is true to say that being a mammal does not catch the full essence of man, Aristotle's point is rather that being a mammal does not catch the essence of being able to perceive or, more precisely, does not catch the essence of man-qua-being-ableto-perceive. ${ }^{42}$ This last point can be highlighted if one considers the way this explanandum may be introduced in the ordinary language. It is natural to say that one seeks the explanation of man's ability to perceive. (Ordinary language in this case is not an unreliable guide leading us to postulate redundant entities. It is a reliable guide that helps us to focus on the structure of explanations.)

On the other hand, in syllogism 2, all predications are true and even necessarily true in Aristotle's eyes. But, above all, the middle term does express the primary explanation for its explanandum. Being an animal is the primary cause that makes whatever object that is able to perceive be able to perceive. Being an animal also captures the essence of man-qua-able-to-perceive.

Thus, in syllogism 2, the middle term: (i) "cannot be otherwise" in the sense that a primary explanation for the fact expressed in the conclusion cannot be cast with a term other than "animal"; (ii) catches the essence of man qua being able to perceive or the essence of man's ability to perceive. By contrast, the middle term in syllogism 1: (i') "can be otherwise" in the sense that a primary explanation (or even an equally reasonable explanation) for the fact expressed in the conclusion can be cast with a term other than "mammal" (for instance, with "biped" or with "having lungs"); (ii') does not catch the essence of man qua being able to perceive. 
Aristotle's discussion proceeds with very difficult remarks:" [you will then have opinion, not knowledge in the true sense of the word,] both about the fact that and about the reason why, if you have your opinion through immediates; but if you do not have your opinion through immediates, you will only have opinion about the fact that" (89a21-23).

Let me call the first situation opinion through immediates (89a21-22). Aristotle is talking about someone who tries to explain why $C$ is $A$ through premises $(B-A, C-B)$ that are immediates in some way. Now, "immediate" as a predicate for "premises" has many usages in Aristotle's texts ${ }^{43}$ and there is no need to assume from the start that "immediate" in this context means a premise that cannot be deduced from previous premises or a premise that cannot be primarily grounded in prior premises. The latter option is excluded from the fact that, if someone tries to explain why $C$ is $A$ through premises that are true and cannot be primarily grounded in prior premises, one does not have opinion, but knowledge in the truest sense of the word (that is, demonstrative knowledge). Actually, Aristotle has already said at 89a3-4 that opinion "grasps an immediate but not necessary premise" 44 and two other passages, 78a26-8 and 75a16-17, present explanations that proceed through "immediates" but do not attain scientific knowledge. ${ }^{45}$ The expression "immediate premise" is sometimes used as equivalent to a premise which, although it could or should have been grounded in prior premises, was not taken in this way in a given context. So, for example, in Prior Analytics 48a33-8, where "triangle has $2 \mathrm{R}$ " is given as an example of a sentence taken (in this case, mistakenly) as immediate. ${ }^{46}$ In other cases, "immediate premise" means a predicative premise in which the relation between its terms is immediate in the sense that, even if it can be deduced from other premises, it does not need to be deduced (because it is obviously true).

Let us take a look at 78a26-8, where Aristotle is explaining a distinction between knowing that and knowing why inside the same science: "in a second way, [sc. knowing that is different from knowing $w h y$ ] if, although the syllogism does proceed through immediates, it does not proceed through the cause but through the more familiar of two convertible terms" (Barnes's translation with modifications). 
There can be little doubt that Aristotle has in mind a situation like the one illustrated in the syllogism given in 78a28-38: the major and the middle term are coextensive with each other (so that the major premise is convertible), but there is an explanatory asymmetry between them, since one is the cause of the other but not the other way round. If someone who tries to explain why the planets are near the Earth proposes the description "not twinkling" as middle term, one fails at catching the appropriate relation of causality between the coextensive terms. ${ }^{47}$ It is the property of being near the Earth that grounds the property of not twinkling, but not the other way around. Nevertheless, the major premise in this attempted explanation, "all not-twinkling [celestial bodies] are near the Earth", which is convertible into "all [celestial bodies] near the Earth are not-twinkling", is described by Aristotle as an immediate premise in 78a26-8. At 78a33-5, Aristotle says that this premise is attained through induction or through perception. This remark suggests that this premise may be understood as an "immediate" premise in the sense that it can be attained directly - in this case, via perception. Now, saying that a premise is "immediate" in the sense of "directly attainable" or "perceptible" is not the same as saying that a premise is immediate in the sense that it cannot be deduced from previous ones. Actually, if there is a third description coextensive with "near the Earth" and "not twinkling", the premise "all not-twinkling [celestial bodies] are near the Earth" can easily be deduced from previous ones. ${ }^{48}$ Thus, it is clear that Aristotle is talking about premises which are immediate in the sense that they need not be deduced from previous ones, but not in the sense that they cannot be deduced from previous ones.

Another way of understanding this talk of "immediate" premises leads eventually to the same results. "Immediate" in some cases points to a premise which, although it can be attained through a middle term (i.e., can be deduced from previous ones), was not taken in this way in a given argument, but was rather assumed (see an analogy in 76b27-31)..$^{49}$ In such a case, Aristotle's focus when he calls a given premise "immediate" is the attitude of its proponent. A particular case of such an attitude is the case in which one believes that his premises reach the primary explanation: one claims that his premises are "immediate" in the sense of not being grounded in prior premises. 
Thus, when Aristotle says at 89a20-22 "if you have your opinion through immediates" ("ean men dia ton ameson doxazei"), he is envisaging one of these situations: (i) when one attempts to explain why $C$ is $A$ through premises that can be attained directly (and need not be deduced from previous ones) but do not catch the primary cause, one does not have knowledge (in the truest sense of the word), but has only opinion about the fact that $C$ is $A$ as well as about the explanation why $C$ is $A$. Alternatively, (ii) when one believes that he has reached the primary premises that explain why $C$ is $A$ but those premises actually do not catch the primary cause, ${ }^{50}$ one does not have knowledge (in the truest sense of the word), but has only opinion about the fact that $C$ is $A$ as well as about the explanation why $C$ is $A$.

This picture fits well what Aristotle has said in a passage from Posterior Analytics A-6 which employs a similar language: "it is clear that you must have the demonstration through a middle term which is necessary; otherwise, you will not have knowledge of the reason why, i.e., that it is necessary for that term to be the middle term: (i) you will then either think that you have knowledge without having it, if you believe to be necessary a middle term which is not necessary, (ii) or you will not even think so, similarly whether you grasps the fact that through nonimmediates or one reason why, even if through immediates" (75a12-17). (My own translation).

In order to have scientific knowledge about $C$ 's being $A$, one must demonstrate it through the necessary middle term - the middle term that cannot be replaced with a different one. Otherwise, if one attempts to demonstrate it through another middle term, one will not know the primary explanation, nor will know that it is necessary for that term to be the middle term in a demonstration. Now, if one believes that he has grasped as necessary a middle term that is not the necessary one, one will believe that he has scientific knowledge without really having it. This situation (or a similar one, in which one would not even claim to have reached scientific knowledge) will hold indifferently whether one grasps that $C$ is $A$ through premises that are not even immediate (cf. 78a23-6) or one grasps some explanation why $C$ is $A$ through premises that are immediate according to the usages of "immediate" I have outlined above. 
Let me come back to A-33. There is a second situation, which may be labelled opinion through non-immediates (89a22-3). Aristotle says at 75b3640 that immediate premises might fail at capturing the relevant principles of each thing qua itself. When he illustrates a case in which one knows that without knowing why, he also stresses that being immediate is a necessary but not sufficient condition for being a primary cause: "if your syllogism does not proceed through immediates (for, in this case, the primary cause is not captured, but knowledge of the reason why comes from the primary cause)" (78a24-6). A primary cause must be "immediate" in the sense that its logical relation with its proper explanandum needs not be established from previous premises. Now, being immediate in this logical sense does not entail the explanatory primacy Aristotle attributes to primary causes, but is surely a necessary condition for it. ${ }^{51}$ If one attempting to give an explanation presents middle terms that are not immediate even in this logical sense, one is far from attaining the primary cause and, consequently, is far from reaching scientific knowledge.

The problem is that, in our passage, Aristotle seems to say something even more strict than that: "but if you do not have your opinion through immediates, you will only have opinion about the fact that" (89a22-23). Aristotle seems to imply that the absence of immediate premises prevents someone from having even a wrong opinion about the reason why.

There are two possible ways of handling this. One option is to take the adverb "monon" with "doxazei", not with "hoti". The result will be the same as the former situation: "one will have only opinion [but not knowledge] about a given fact", and it would be implied in the context: "as well as about the explanation of the fact". It might be objected against this move that it makes the bifurcation of the argument pointless. ${ }^{52}$ There is no real difference whether one selects "immediate premises" (ean men) or "non-immediate premises" (ean de): in both cases one will have only opinion but not knowledge about the fact that and the reason why $C$ is $A$. However, this indifference seems to be exactly Aristotle's point in 75a16-7: if one does not grasp the necessary middle term, one does not have knowledge whether he claims to know that $C$ is $A$ through nonimmediates or he claims to know why $C$ is $A$ through immediates. The variation from "non-immediates" to "immediates but not primary" does not produce any relevantly different result. 
Another option is to take the term "ameson" in this case as a sign of lack of a full explanatory claim. The idea would be the following: when someone who is looking for causes reaches the point where he is satisfied and does not proceed asking why (see for this picture 85a27ff.), he reaches an "ameson" (a premise that cannot be explained by a prior one or at least is thought to be so) and claims to have a full explanation. This use of "ameson" marks the claim of having reached a causal relation which does not depend on a previous one (see 85a28-9). Now, it makes sense to say that, if one does not reaches an "ameson" in this sense, one does not even claim to have an ultimate explanation. This is compatible with the fact that the opiner might still be said to have some opinion about the explanation why $C$ is $A$ as far as he concludes that $C$ is $A$ through true premises (no matter what these premises are).$^{53}$

Although the latter option is plausible, the former one is preferable because it is in harmony not only with its immediate context in the chapter but also with what Aristotle says at Posterior Analytics A-6.

\section{6.}

There are two exegetical difficulties about the awkward terminology employed in Posterior Analytics A-33. I believe my interpretation would become more satisfying if it can explain away this terminology in a coherent way.

The first awkwardness is in the following passage: "for instance: knowledge is of that which man precisely is, whereas opinion is of man, but it is not of that which man precisely is; the thing [sc. which is the object of both knowledge and opinion] is the same, because it is man, but the way [sc. in which man was taken] is not the same" (89a35-7).

I have argued that in 89a33-7 "man" is the C-term for both knowledge and opinion, whereas "animal" is the B-term for knowledge. The fact that "man" is "the same C-term" both for opinion and knowledge is essential to guarantee the analogies with the true-or-false-opinion case. In turn, the expression "to d' hos" suggests that the description (or ratio sub qua) under which man's being A was explained is different in each case, that is, the $B$-term is different for opinion and knowledge: something 
like "mammal" might be the middle term for opinion, whereas "animal" will be the middle term for knowledge, like in the Syllogisms 1 and 2 respectively.

But it still remains to understand the awkward expression "hoper anthropou". First of all, important syntactic remarks are required:

- the expression is a compact abbreviation of "toutou hoper anthropos estin". ${ }^{54}$

- the relative pronoun "hoper" works as predicate, not as a subject. ${ }^{55}$

- the fact that "anthropou" is in the genitive cannot be explained by any relation "anthropos" has with "hoper"; the genitive is rather explained by the fact that "hoper anthropou" replaces "zoou", which was a genitive depending on "episteme" (implied in "he men" at 89a33).

Besides, and most importantly, the force of the pronoun "hoper" is not merely to point to what man essentially is (as most interpretations assume),$^{57}$ but to restrict our attention to man as having the attribute to be explained. In this context, the pronoun "hoper" points to that which man precisely is as being able to perceive, i.e., it points to the feature that makes man able to perceive (so to speak, it asks for the feature that makes man precisely able to perceive).$^{58}$

In this way, "hoper anthropou" is a description that points to the superiority of the middle term for knowledge as opposed to the middle term for opinion, which is not "hoper anthropou". The translation of these expressions is the following:

(E1): "hoper anthropou": "that which man precisely (sc. as being $A$, able to perceive) is";

(E2): "me hoper anthropou": "not "that which man precisely (sc. as being $A$, able to perceive) is"”.

Now, it is not clear that "animal" must be supplied at $89 \mathrm{a} 34-5$ as an implied term in the object of opinion, as most interpreters assume. The Greek text omits "animal" so that the sentence can be taken in the following way: "opinion is of [a given middle term] in such a way that [this middle term] can be otherwise". Let me take up the examples I have introduced before:

Syllogism 1: (Opinion)

Every mammal is able to perceive 
Every man is mammal

Every man is able to perceive

Syllogism 2: (Knowledge)

Every animal is able to perceive

Every man is animal

Every man is able to perceive

The expression (E2) "me hoper anthropou" picks up the middle term in syllogism 1: opinion comes from grasping something that is not "that which man precisely (sc. as being able to perceive) is". The force of expression (E2) is not to imply that mammal is not an essential predicate of man or that "mammal" does not tell us "that which man essentially is"- and this is a strong reason to reject the assumption that the pronoun "hoper" merely points to essential predicates. ${ }^{59}$ Although it is true that mammal is not an essential predicate of man (at least in the sense of being one of the elements of the definiens account of man), the force of (E2) is rather to suggest that mammal is not that which man as (precisely) able to perceive is. Mammal is not the attribute that makes man able to perceive and, therefore, is not the attribute needed to explain why man is able to perceive.

Another paper will be required to calm down strong skepticism against my exegetical claim. I stress that I am not claiming that "hoper X" has always this meaning. I do claim that "hoper" always (or almost always) plays the role of predicate in "hoper X", as I have highlighted above. But I do not claim that the expression always has this full meaning independently of context (or independently of which concrete term replaces " $X$ "). I do claim that the relevant usage of "hoper $X$ " is a second-order remark about some properties of a predicate of subject $X$, and a remark that always brings together a third implicit predicate. Thus, " $A$ is hoper $X$ ” presupposes the following sentences in a first-order level:

(1) $X$ is $A$ ("man is animal");

(2) $A$ is $Y$ ("animal is able to perceive");

(3) $X$ is $Y$ ("man is able to perceive"),

and actually remarks, at a second-order level, that the predicate $A$ in (1) not only allows the transitivity to (3), but also picks up what $X$ is in order to explain why (3) is true. In other words, " $A$ is hoper $X$ " presupposes that 
" $X$, being $A$, is $Y$, since $A$ is $Y$ " and describes a second-order property that $A$ has in this triadic context. Thus, "animal is hoper man" presupposes that "man, being animal, is able to perceive, since animal is able to perceive", and describes a second-order property "animal" has: the property of being the relevant factor which explains why (3) is true.

What I am claiming about "hoper anthropos" can be better understood from Metaphysics VII-4, 1030a3 and ff. The language of both contexts is formulated as if it were in a second-order level, describing some features of predicative or explanatory relations between terms. In 1030a3ff., Aristotle says that "white man", as a putative definiens account of "cloak" (a name arbitrarily stipulated for the class of men who are white), is not "hoper tode ti" (what "a this" is) in the sense that "white man" does not tell what a substance is and in the sense that its elements are so related that "one is said of the other". In turn, a description which picks up a species of a genus is "hoper tode $t i$ " in the sense that it does tell what a primary thing (a substance) is. ${ }^{60}$ Similarly, in Posterior Analytics 89a35-6, the usage of "hoper anthropos" is saying, at a second-order level, that animal, as a predicate of man and as a middle term in a given explanation about one of man's attributes, does tell what man precisely (i.e., qua having the attribute to be explained) is.

It is the context of 89a35-6 that makes it clear that "hoper anthropos" is pointing to the C-term qua having the attribute introduced by the $A$-term. The reference to a given $A$-term is required to make any concrete middle term to be the necessary one. No middle term could be labelled "the necessary one" - the middle term that catches the primary cause - without reference to a given $A$-term to be explained. Take "mortal" instead of "able to perceive" as the $A$-term. The explanatory power of animal will be diminished, since it is not being an animal that primarily explains why man (or whatever entity) is mortal. Since mortality is to be explained in terms of liability to corruption, being a sublunary living being made out of the four elements is a better candidate for "the necessary middle term" than being an animal. Aristotle's discussion seems to take the description "what cannot be otherwise" as interchangeable with "hoper anthropos" ("what man precisely is"). But this interchangeability with "hoper anthropos" can only be accounted for if an implied reference to a given $A$-term is assumed inside the description "hoper anthropos": 
animal is "what cannot be otherwise" as well as "hoper anthropos" only in reference to a given $A$-term.

It is clear, therefore, that the expression (E1), "hoper anthropou", picks up the middle term in syllogism 2: knowledge depends on grasping a middle term which is "that which man precisely (sc. as being able to perceive) is". The force of expression (E1) is not merely to imply that animal is an essential predicate that tells us "what man essentially is". The force of (E1) is rather to suggest that animal is that which man as (precisely) able to perceive is, in other words, animal is the exact attribute one needs in order to explain why man is able to perceive.

I cannot develop this further claim here, but this interpretation allows us to understand most of what Aristotle means when he uses expressions such as "the principles of that thing qua that thing" (76a5-6). The referent of "that thing" is most commonly taken to be the $C$-term, but I argue that the referent is rather $C$-qua- $A$, or $A$ (-of-C): for instance, "man-quaperceptive", or the "man's perceptiveness"; "cloud qua noisy" or "such and such noise in the clouds".

\section{7.}

Syllogisms 1 and 2 also allow us to understand Aristotle's final remarks in the chapter. When he rejects the counterfactual situation in which one would have opinion and knowledge at the same time, his descriptions of each cognitive state is the following: "one would grasp at the same time, for instance, (i) 'because man is that which animal precisely is' (this was the meaning of 'to be impossible for the middle term not to be animal') (ii) "not because man is that which animal precisely is" (89b3-7). (This is my own controversial translation, which will be discussed).

"Animal" is still the middle term for having knowledge of a given attribute of man, but now Aristotle uses the expression "that which animal (precisely) is" instead of "that which man (precisely) is". The shift can be explained from the difference in the context. In 89a35-6, Aristotle's usage of "hoper anthropos" ("that which man precisely is") was at a second-order level: he was accounting for the property which makes animal (as middle term) "the necessary middle term": animal is necessary because it tells 
what man as being-able-to-perceive is. Now, at 89b4-5, Aristotle's usage of "hoper zoon" ("that which animal precisely is") is in a first-order level. Take the same triplet of first-order sentences as before, namely:

(1) $X$ is $A$ ("man is animal");

(2) $A$ is $Y$ ("animal is able to perceive");

(3) $X$ is $Y$ ("man is able to perceive").

When Aristotle introduces the sentence "man is that which animal (precisely) is", he is explaining why (3) is true - which amounts to explaining why the conclusion of syllogism 2 is true. In fact, "hoti" at $89 \mathrm{~b} 4$ is a "because", not a "that". The description "that which animal (precisely) is" is extensionally equivalent with the term $Y$ ("able to perceive"), but the point of using the sentence "man is that which animal (precisely) is" is exactly to describe (3) in a way which highlights it as a result of premises (1) and (2): man is able to perceive, but the point at $89 \mathrm{~b} 4$ is to explain that man is such (i.e., able to perceive) because it is that which animal precisely is, and that which animal precisely is corresponds to being able to perceive. Thus, there is a triadic explanatory context at $89 \mathrm{~b} 4-5$. The form of the sentence "hoti ho anthropos hoper zoon" (89a4) should be taken in this way:

- because ("hoti") C ("ho anthropos") is what B is ("hoper zoon");

In this triadic context, the relative pronoun "hoper" works as predicate of "zoon" and is the sign of the transitivity from " $B$ " to " $A$ " in relation to the subject $C$ : man, being that which animal (precisely) is, turns out to be able to perceive. From a mere extensional point of view, the description "that which animal (precisely) is" refers to the $A$-term. But this description points to the $A$-term through its being grounded on the $B$-term: the $A$-term is "that which the $B$-term precisely is", so that in the triadic framework of the explanation to say that $C$ is "hoper $B$ " amounts to explaining that $C$ is $A$ because of its being $B$. Thus, being an animal is exactly the feature that fully and appropriately explains why man is able to perceive, and this is compatible with the fact that the term "animal" animal was described (at a second-order level) as "hoper anthropos", i.e., as the necessary middle term that tells what man qua (precisely) being able to perceive is.

Let me return to the contrast between demonstrative knowledge and explanatory opinion. Both demonstrative knowledge and opinion have as 
their exact object that $C$ is $A$ because of its being $B$. The sentence at 89b3-5 describes the knowledge-case:

- in the case of knowledge, one will grasp (that man is able to perceive) because man is that which animal is; and Aristotle remarks that he has already explained (en, 89b4) that this was what he meant when he said that it is not possible for the B-term not to be animal, i.e., it is not possible for the B-term to be a thing other than animal; thus, "animal" turns out to be the middle term that cannot be otherwise. ${ }^{61}$

On the other hand, the sentence at $89 \mathrm{~b} 5$ describes the opinion-case. The same "hoti" from 89b4 must be understood here and taken as the object of the negation ("me"), so that this elliptical sentence should be taken as denying that "animal" is taken as middle term in the explanation offered by the opiner:

- in the case of opinion, one will grasp (sc. that man is able to perceive) not because (man is) what animal precisely is. One fails at catching the appropriate middle term, "animal". And this failure is then related to a failure concerning the "modal" requirement: the $B$-term picked up by the opiner, "mammal", might have been another one, like biped, or having lungs. "Mammal", then, turns out to be a middle term that can be otherwise.

Aristotle's account of the difference between demonstrative knowledge and opinion, therefore, is entirely in terms of explanatory relevance and does not depend on any epistemological notion, nor does it depend on interpreting the modality of basic predications. ${ }^{62}$

${ }^{1}$ Barnes's translation with modifications. I use "knowledge" instead of "understanding", and further on it will be clear that the knowledge at stake is scientific or demonstrative knowledge (not knowledge in general).

2 The next paragraphs give a brief account of what I have argued for in Angioni (2013a). Barnes (1993, p. 19) says that "A 33-4 turn from the theory of demonstration to more general epistemological matters", but actually there is no general epistemological approach in A-33. Gerson (2009, p. 62-89) offers a general account about the epistemological distinction between knowledge and belief in Aristotle, but I disagree with almost everything he has said about the Posterior Analytics. I see no evidence for his restricting doxa to what he calls accidental identities (p. 69). For an account in the traditional line, see Porchat (2000, p. 40-2) and Kiefer (2007, p. 121-2). Epistemological approaches may be found at the physical treatises, i.e., On the 
Soul, On Memory etc., but it is clear that Aristotle has dismissed them from the issues discussed in Posterior Analytics A-33 (see 89b7-9). On the place of epistemology in Aristotle's general theory of demonstration, I agree with Kosman (1973), Burnyeat (1981), p. 108-115, Taylor (1990) and Matthen (1981), p. 3-10: the problem of justification of knowledge claims is not central to Aristotle's project, which is rather based on the notion of primary explanations based on real-world causal relations. See a more recent approach on this subject in Fine (2010b).

${ }^{3}$ See Fine (2010a, p. 326-7) for a similar view: episteme is used in Posterior Analytics A-33 for "high level knowledge", whereas doxa is used for mere belief ("belief that falls short of knowledge"). See also Fine (2010b, p. 133-4).

${ }^{4}$ I use "explanation", "explanatory" etc. in this paper in accordance with Aristotle's theory of causality. To explain $X$ is to report a real world factor that makes $X$ what it is, and this factor is the cause of $X$. Other things that may count as explanations in a looser sense do not count as explanations in this Aristotelian sense. To elucidate the meaning of a given expression, for instance, does not qualify as an explanation in this restricted sense.

${ }^{5}$ Barnes 1993, p. 198-9, works mostly with a propositional approach: $p$ is the form of what one knows through opinion or knowledge (see also Fine 2010a, p. 324, 332-5). I argue that this is not enough to understand what Aristotle is proposing. On the other hand, Barnes (1981) was responsible for the current mainstream which rejects syllogistic as a framework for demonstrations.

${ }^{6}$ I have argued more carefully for this understanding of the "necessity requirement for knowledge" in Angioni (2007, p. 23-4), as well as in Angioni (2009, p. 66-71) and Angioni (2012, p. 44-7).

${ }^{7}$ This is Barnes's translation with slight modifications.

${ }^{8}$ This assumption, which was already at work since the beginning of the chapter, is unjustifiedly ignored by Gerson (2009, p. 68-70) when he restricts belief to what he calls "accidental identities", which (if I have understood him rightly) amount to predicative ties between a particular subject and a particular property. No matter what Gerson exactly means by "accidental unities", my worry is that for him doxa at Posterior Analytics A-33 is not concerned with explanations of why a given predication is true. Philoponus (322.32-323.5, 327.8-12) seems to have understood this assumption.

${ }^{9}$ A similar approach can be found at Peramaztis (draft, p. 5, 8): claims of knowledge will have the form "knowing of/about x, because of its being E, that it is F". But I disagree with Peramatzis because I take the opinion at stake in APo A-33 to have a similar triadic explanatory form (opinions which simply lack an explanatory claim being out of the picture in A-33).

${ }^{10}$ I have discussed this issue in Angioni (2012, p. 8-9 ss.). My thesis is that Aristotle has selected the syllogism as instrument of demonstration because a syllogism is able to display causal relations and the most important point in Aristotle's conception of science is the requirement of knowing something through its primary cause. Other formal properties of syllogistics, like completeness, liability to axiomatization, etc., are of no interest in the theory of demonstration. A similar approach was developed by Matthen (1981, p. 4-10). A very different approach can be found at Hintikka (1972, p. 55-7). Barnes (1981, especially p. 33-4) has started an anti-syllogistic approach that has made scholars overlook the importance of triadic causal 
explanations in Aristotle's theory. A more interesting account was given by Lear (1980, p. 104), although I disagree with his claim that Aristotle's motivation in syllogistics was to "shed light on the nature of proof" (p. 13).

${ }^{11}$ As textual basis for this, see Posterior Analytics B-2, 90a5-23.

12 Note that " $e$ " in 89a16 points to a strong rejection of the hypothesis suggested at 89a13-14, that the knower and the opiner will accompany each other through the same middle terms.

${ }^{13}$ What Aristotle labels "doxa" at Posterior Analytics A-33 is compatible (if not identical) with what many philosophers will call "knowledge". "Opinion" in this context might be the same as "eidenai hoti p" in the way Fine (2010b, p. 142-3) has characterized it: "justified true belief, [...] where the justification must be at least as strong as having a good argument for $p$ ". I add on my part: "where the justification falls short of catching the primary cause for $p$ ". As Fine (2010b, p. 148) says: "one knows that p is true [...] when p is true, one believes that $\mathrm{p}$ is true, and one has a good argument for believing that $\mathrm{p}$ is true, though (if one doesn't also know why $\mathrm{p}$ is true) the argument falls short of explaining why $p$ is true". I argue that doxa in Posterior Analytics A-33 is exactly knowledge of this sort. I will also go further to the point of saying that this sort of knowledge is exactly what is described as "kata symbebekos" or sophistical knowledge at 76a1ff. and 74a25-32, and in this respect I disagree with Fine (2010b, p. 1468). I have argued for such a view of kata symbebekos knowledge at Angioni (2007) and (2009).

${ }^{14}$ Barnes's translation with modifications.

${ }^{15}$ This is my own translation of Aristotle's text.

16 There is no need of Topics I-7 and Metaphysics V-6 and V-9. I agree with Barnes (1993, p. $200)$ in this point: "these passages throw no light on the present argument".

${ }^{17}$ I take to ti en einai hekateroi at $89 \mathrm{a} 32$ to refer to the essence of each opinion (the referent of "hekateroi" is "doxazein" at 89a30), that is, the true opinion about the diagonal being not-commensurate and the false opinion about the diagonal being commensurate. See Philoponus (329.19-20), Barnes (1993, p. 201) and Fine (2010a, p. 336). Others, like Ross (1949, p. 6068), Pellegrin (2005, p. 395-6) and Mignucci (2007, p. 247), take the expression to refer to the essence of the diagonal as subject in both predicative statements.

${ }^{18}$ An analogy means that there is the same relation between two pairs of relata or that there is one and the same description for the relations between two pairs of relata. For instance, as 6 is to 2, so 9 is to 3 . The relation in question can be described as "being the triple of". Similarly, as the sunset is to the day, so the old age is to life. This is what grounds the metaphor in saying that "the sunset is the old age of the day" or "the old age is the sunset of life" (Poetics 1457b16-25). All that is required for an analogy is that both relations can be relevantly described in the same way, even if there are differences between them. Besides, nothing prevents one or more terms of the analogy from being complex. Consider, for instance: as Maria is to Peter and John, so Rhea is to Fido and Dido. The relation might be: "being the beloved one of both", or "being born before the first but after the second". Now, in the comparison at Posterior Analytics A-33, what are the relevant relata and the relevant descriptions of their relations? I will argue in the following paragraphs that there are actually two analogical comparisons.

doispontos, Curitiba, São Carlos, vol. 10, n. 2, p.255-290, outubro, 2013 
${ }^{19}$ Why I do not distinguish (1) and (2) straigthtforwardly in terms of the distinction between objects and propositions, like Fine (2010a, p. 337) does? As it will become clear, I stress that "to auto" can also refer to an explanation in triadic form. My proposal might seem to have some similarity with what Fine (2010a, p. 342) has labelled Truncated versus Full Proposition view (TFP), since a proposition of the form " $C$ is $A$ because of its being $B$ " might be considered as a Full one, whereas " $C$ is $A$ " might be taken as a Truncated one. But there is a great difference between TFP and my own view. Although an explanation can still be described as a complex or full proposition, I argue that it is philosophically and exegetically interesting to stress the contrast between a merely predicative proposition and an explanation in triadic form (see more on endnote 28), since that contrast will allow us a better understanding of what "necessary" means in this context. My view is not be liable to the right criticisms Fine (2010a, p. 342) has raised against TFP: my opiner will not be committed to accept that "man is not necessarily an animal".

${ }^{20}$ That is my main disagreement with Fine (2010a, p. 341-3), who favours her SODP on the premise that it preserves the parallelism with the discussion of true and false belief in a better way than TFP and SPDM - as if exactly the same situation should apply to both cases discussed. I do not think a strict parallelism (in the sense of identity of the relations involved) is required for the analogy (see endnotes 18 and 22).

${ }^{21}$ This is where I disagree with most interpretations: if ones take a single predication as the object to be compared, one will be tempted to account for the difference between knowledge and opinion in terms of modality, like Ross (1949, p. 608) and Mignucci (2007, p. 247, who believes that the content of knowledge is " $P$ is necessary", while the content of opinion is " $P$ is not necessary"). Also Fine (2010a, p. 332, 335) goes along these lines, although she offers a refined critical discussion of many options. The modal interpretation is as old as Philoponus (326.3-6, 328.19-22 ff.). See my sections 3-4 for discussion.

22 Similarity (not identity) is at stake for most analogies: for instance, the relation between sunset and day is similar to, but not identical with, the relation between old age and life. There are many differences: days are measured in hours, whereas a lifetime is measured in years; days are not a state of any living being, whereas life is the state of a living being etc. Nevertheless, the relations share a relevant common feature that can be highlighted in a common description, which is enough for the analogy.

${ }^{23}$ Some scholars might agree with this, as they attempt to account for the difference between knowledge and opinion in terms of extra-content features (like modality) of an elementary predication. See Ross (1949, p. 608:"A. has pointed out that a true and a false judgment with the same subject and the same predicate must differ in quality. He now insists that knowledge and opinion about the same subject and the same predicate differ in modality", my italics); Porchat (2000, p. 42), and Mignucci (2007, p. 247), who argues that the object of knowledge is " $P$ is necessary" whereas the object of opinion is " $P$ is not necessary". See Fine (2010a, p. 337-343) for an excellent critical discussion of most of these approaches. Barnes (1993, p. 200-2) has a different story: he starts with a "propositional approach", but then moves to a "predicative approach" in which the predicate in the object of knowledge and opinion cannot be the same. He actually takes the analogy in a wrong way when he uses his (10) to attain his (12), which is equal to my (4). It is difficult to understand why scholars have not used the syllogistic framework of explanations at this point.

doispontos, Curitiba, São Carlos, vol. 10, n. 2, p.255-290, outubro, 2013 
24 Or, alternatively, "C-qua-B”.

${ }^{25}$ An interesting alternative is developed by Peramatzis (draft): he challenges the traditional notion of necessity and argues that the necessity at stake, which a knower grasps and an opiner falls short of grasping, is "essence-based" and derivative, so that Aristotle's main focus is on causal relations explained by the essences of subjects.

${ }^{26}$ This is my own translation. Along the same lines, see Ross (1949, p. 606): "the object is the same because it is in both cases man". Barnes's translation suggests (or at least leaves it open) that "to auto" at $89 \mathrm{a} 36$ refers back to knowledge and opinion, but not to the "material object" of both. I cannot understand what has led Mignucci (2007, p. 248) to say that Barnes's suggestion for "tou autou" was required because the option favoured by Ross and me "ha poco senso perché richiede come soggeto sottinteso 'il contenuto dell' opinione e il contenuto della conoscenza scientifica",.

${ }^{27}$ There is no need to supply "animal" at 89 a34-5 as the supposed object of opinion.

${ }^{28}$ One might argue that my interpretation in the second analogy collapses into what Fine (2010a, p. 338-40) has labelled SODP (same object, different proposition). The collapse depends on taking " $C$ is $A$ because of its being $B$ " as a single proposition. I admit that SODP would hold in this way. But my point is that to reduce " $C$ is $A$ because of its being $B$ " to a single proposition and consequently to say that SODP holds of knowledge and opinion leads us to miss something relevant for our philosophical understanding of the issue. If I am right, it would be a leap to conclude that Aristotle is committed with a Two World Theory for propositions, because it is not clear how Aristotle individuates propositions. As I will argue in my next sections, an opiner grasps that (a) "every man is mammal" is true, that (b) "every mammal is able to perceive" is true and that (c) "every man is able to perceive" is true, as well as he grasps that (d) "every man is able to perceive because of its being mammal" is true (in the sense that it gives at least some reasonable explanation). Now, a knower knows that (a') "every man is animal" is true, that (b') "every animal is able to perceive" is true and that (c) "every man is able to perceive" is true, as well as he knows that (d') "every man is able to perceive primarily because of its being animal" is true (since it presents the primary explanation). But there seem to be no reason to deny that the same knower also grasps all the truths the opiner grasps, i.e., that (a), (b) and even (d) are also true. If there is a TWT in this case, it is not one that would allow us to say that the opiner somehow grasps what the knower grasps (Fine, 2010a, p. 334), since the opiner cannot grasp the truth of (d'), even if he grasps that (a') and (b') are true; on the contrary, it would be a TWT in which the knower also grasps what the opiner grasps. The core of the difficulty is how to understand (d) and (d'). The Propositional reading Fine (2010a, p. 324) defends distinguishes knowledge and belief "in terms of the truth implication of their contents". In my reading, truth implication is not enough as a rationale for the distinction (maybe because it is difficult to understand what is involved in saying that propositions like (d) and (d') are true): episteme is distinguished from doxa rather in terms of the relevancy of the explanatory factor included in their contents.

${ }^{29}$ Aristotle is not concerned with the modal status of the predication "man is animal" taken in itself, pace most interpreters since Philoponus (329.22-24). See Ross's commentary (1949, p. 606, 608): "knowledge is 'of animal' as a predicate that cannot fail to belong to the subject"; Mure's translation: "knowledge is the apprehension of, e.g. the attribute 'animal' as incapable

doispontos, Curitiba, São Carlos, vol. 10, n. 2, p.255-290, outubro, 2013 
of being otherwise"; Pellegrin's: "La première [sc. science] en effect a comme objet l'animal de sorte qu'il ne soit pas possible que le sujet ne soit pas un animal" (in a note at p. 396, he adds that the subject is "l'homme"); Mignucci's (2007): "la prima [sc. conoscenza scientifica] è dell'animale in modo tale che l'uomo non può non essere animale". See also Gerson (2009, p. 70); Harari (2010, p. 58). It will also be wrong to translate in this way: "knowledge is of animal in such a way that it is not possible [for animal] not to be an animal". Barnes's translation ("the former [sc. knowledge] is of animal in such a way that it cannot not be an animal") is compatible with this latter option.

${ }^{30}$ This example for a A-term is only illustrative and might be replaced with any other such as "mortal", "breathing" or "able to learn grammar" etc. Aristotle actually never mentions the A-term in the most relevant contexts in APo A-33. In my final sections I will show how I am justified in thinking that the A-term is always presupposed in these contexts.

31 The same story holds for "mesou anankaiou" at 75a13: when Aristotle calls a middle term "necessary", he is not focusing on the mere predicative tie between this term and its subject (in the minor premise of a Barbara); he is rather focusing on its explanatory role qua middle term: as such, i.e., as a middle term responsible for the explanation of a given conclusion, a middle term is "necessary" in the sense of being the middle term "required for an appropriate explanation", which amounts to being the middle term that catches the primary cause of what is to be explained. Traditional approaches like Lloyd (1981, p. 157-61), are not sensitive to this triadic usage of "necessary".

32 I disagree with Barnes (1993, p. 201), who believes that Aristotle's use of the expressions "episteme/ doxa + genitive" is not consistent through the chapter A-33: he complains that those expressions at 89a34-6 denote the predicate of a proposition, while in earlier uses it denoted the proposition itself. Both of his claims are wrong, for Aristotle is always using the expressions "episteme/ doxa + genitive" to introduce cognitive states about the triplet which underlies syllogistic explanations. What comes in the genitive is ultimately a shortcut for that $C$ is $A$ because of $B$. It may be said that knowledge is of $B$ because $B$ is the most important factor on which knowledge depends. It may also be said that knowledge is of $\mathrm{C}$ because $\mathrm{C}$ is the raw subject-matter, as well as that knowledge is of $A$ because $A$ is what one knows about $C$. But, ultimately, knowledge as well as opinion in this context are always of the triplet " $C$ is $A$ because of its being $B$ "'

${ }^{33}$ This is my own translation. Important points about philological difficulties will be addressed in the main text.

${ }^{34}$ See Metaphysics Z-4 1030a17: the wrong assumption, in this case, is that primary definitions (as well as primary essences) are the only definitions. See also Posterior Analytics 85b4, 95b7, 98b32, Metaphysics 1033b21, 1034b32, 1039a21, 1044b36.

35 See Ross (1949, p. 607).

36 See translations along these lines in Ross (1949, p. 605), Barnes (1993, p. 48), Mignucci (2007, p. 89), Pellegrin (2005, p. 233) and even in my old translation in Angioni (2004, p. 72). Now, it is not clear what this could mean. Did Aristotle mean that we grasp definitions immediately? Was his point an epistemological one? Barnes (1993, p. 200) suggests that the point of 
the comparison with definientia was to stress that the "predicates which are necessary to some given subject" are per se predicates.

${ }^{37}$ See Barnes (1993, p. 46). Another option is to read with manuscript M "echein". In this case, "hosper echein tous horismous" will still be a complement of the verb "hypolepsetai" but will be correlated with "allos echein". Translation: "if one grasps that which cannot be otherwise in this way, as he understands that the definitions through which demonstrations proceed are".

38 This result shows an inner unity in Aristotle's theory of demonstration, since it allows to understand how the causality requirement and the necessity requirement work together in the definition of scientific knowledge in 71b9-12. I have explored this in Angioni (2007, p. 2ff.). Lloyd (1981, p. 157) sees that in Aristotle's definition of demonstrative knowledge in 71b9-12 the "necessity requirement" is better ascribed to the cause, but he understands it as equivalent to the traditional modal requirement that the premises must be necessary predications.

39 "Kata" can (and in this context must) be taken as equivalent to a causal-explanatory "dia", as Aristotle makes it clear in passages such as Posterior Analytics 73b10-6, 75b34-7, as well as Topics 116b35-6, 117a1, 118b23-6.

${ }^{40}$ See Peramatzis's sharp remark: "in having a belief or even a true belief about $x$, the believer or true believer either does not grasp at all any essence of $x$ in virtue of which it would necessarily be $F$ or grasps $x$ as being essentially other than what it really is." (draft, p. 5). As I will show, there is still the possibility that the opiner grasps correctly the essence of $x$, but the essence of $x$ is irrelevant or insufficient to yield the primary explanation for $F$.

${ }^{41}$ The "essence of $A$ as attributed to $C$ " might seem an awkward expression with the schematic letters, but consider ordinary expressions such as "the essence of the courage of Spartans" or "the essence of the bipedality of man", as well as "the explanation for the bipedality of man" or "the explanation for the noise in the clouds". It is clear that the $A$-term is the main focus of the essence as well as of the explanation, but the whole explanandum (or the whole thing whose essence is being sought) is the $A$-term as attributed to $C$.

${ }^{42}$ There is no need to be worried with an unwelcome multiplication of essences. It is true that Aristotle only attributes essences in the fullest sense of the word to substances (see Metaphysics 1030a11-7). But it is also true that Aristotle uses the word "ousia" (as well as the expression "to ti en einai") in a weaker way, as pointing to a set of basic features that makes something be what it is and is normally caught in a definiens account. Non-substantial items like relatives have essences in this weaker way (see Topics 146b3-4; see also Metaphysics 1030a17-27, 29-30).

${ }^{43}$ I have discussed this issue in Angioni (2012, p. 12-23). An excellent approach is given by Lear (1980, p. 78-80). See also Matthen (1981, p. 4-10).

44 I have discussed this passage in Angioni (2013a). Barnes (1993, p. 199) has missed the point so much that his verdict about the passage is that "it should be excised". Ross (1949, p. 605,607$)$ has a suggestion that goes in the right direction: an "amesos" premise amounts to an unmediated premise in the sense of not "derived by correct reasoning from necessary premises". What Ross has seen (or at least descried) is that the rationale for this usage of "ameson" depends on the role played by the premises in a chain of explanation. See also Matthen (1981, p. 9-10). 
45 The existence of immediate premises that do not attain knowledge is recognised by Philoponus (327.5-6).

${ }^{46}$ See analogously the use of "anapodeiktois" at Prior Analytics 58a2.

47 See McKirahan (1992, p. 214-6); Koslicki (2012, p. 198-201); Porchat (2000, p. 95-6); Angioni (2010, p. 94-5).

${ }^{48}$ See Prior Analytics B-5, 57b34-7 ff. Aristotle gives convertible terms a lot of attention: Prior Analytics B 8-10 is dedicated to "convertible deduction" (antistrephein, 59b1), and his discussion of circular deduction at Prior Analytics B 5-7 gives prominent place to triplets of convertible terms (cf. 58a12-4).

${ }^{49}$ The analogy with the case developed in 76b27-31 will be the following: as something which is not undemonstrable can be taken as undemonstrated in a given context (as a particular hypothesis or as a postulate) and work as principle for some reasoning, in the same way a premise which is not primary or immediate itself can be taken as primary and immediate and work as a principle in a piece of reasoning. See Ross (1949, p. 540).

${ }^{50}$ There is a parallel situation in $75 \mathrm{a} 14$, which I will discuss in a moment.

51 See Matthen (1981, p. 4), Koslicki (2012, p. 194-5). For a different view of 78a24-6, see Porchat (2000, p. 94).

${ }^{52}$ This objection was addressed to me by Breno Zuppolini and Francine Ribeiro.

${ }^{53}$ I thank Breno Zuppolini for this discussion. Another option is to argue that the restriction of opinion to "hoti" in the case of non-immediate premises should be taken as a rhetorical suggestion not to be followed in its full depth, since Aristotle's broader context is clearly concerned with opinions about explanations (opinions about “dioti").

${ }^{54}$ See Ross (1949, p. 608), Mignucci (2007, p. 248).

55 I have argued in Angioni (2006, p. 125-6) that this is the right syntax for "hoper" in expressions like "hoper X" and "hoper X ti". Ross (1949, p. 608) seems to understand in the same way, but not Barnes (1993, p. 201).

56 See Ross (1949, p. 608), and Mignucci (2007, p. 248). Ross (ibidem) remarks: "But hoper anthropos has through constant usage almost coalesced into one word, so that the genitive inflexion can come at the end".

${ }^{57}$ See Ross (1949, p. 606): "knowledge is of man in his essential nature, opinion is of man but not of his essential nature"; "the one is 'of what man essentially is', the other is 'of man', but not 'of what man essentially is"” (Ross, 1949, p. 608). See also Barnes's translation for "hoper anthropou" ("of just what is man") as well as Barnes's commentary (1993, p. 201): "the object of $b$ 's opinion is 'a man is an animal, but not just what is an animal'". See also Gerson (2009, p. 65,70$)$.

${ }^{58}$ My claim about this expression is restricted to this context (89a35-6). Further discussion of this point will follow.

${ }^{59}$ Gerson (2009, p. 70) claims that the opiner does not achieve knowledge of "man is animal" because he fails to grasps the modal status of it and, more fundamentally, because he fails to 
understand the essence of man as animal. Besides many other issues, this account is not sensible to the real explanatory role an essential predicate (like animal) must play: its explanatory role changes according to the predicate to be explained. For instance: if the explanandum is why every man is mortal, the essential predicate animal is not any more the primary one: mortality is to be primarily explained by the fact that man (or whatever is mortal) is a sublunar living being (made out of the four elements etc.). Thus, essential predicates as middle terms may be insufficient for primary explanations. Gerson (2009, p. 65) would probably not agree with my example, but this is so because he does not consider the requirements for a primary cause as stated by Aristotle in Posterior Analytics A-13.

${ }^{60}$ I have developed this view in Angioni (2013b).

${ }^{61}$ My account is at least preferable to the clumsy attempt given by Philoponus (330.4-9), in which the expression "hoper anthropos" as an attribute of Socrates (!) is taken as implying modality in its meaning.

${ }^{62}$ A draft of this paper was discussed at a seminar in Campinas with my students. I am very grateful to them all, especially to Francine Ribeiro, Breno Zuppolini and Wellington de Almeida, who have raised insightful issues and objections. Part of it was also discussed in seminars in Rio de Janeiro in 2013. I am grateful to Edgar Marques, Rodrigo Guerizoli and Guido Imaguire for helpful questions and criticisms. I am also grateful to Michail Peramatzis for presenting his draft on Posterior Analytics A-33 in Campinas in May 2011, as well as for many discussions on the subject. Thanks also to David Bronstein for helpful discussions on this subject. Finally, I am very grateful to Gail Fine for having sent me an offprint of her paper [2010b].

\section{Bibliography}

ANGIONI, L. 2004. Aristóteles. Segundos Analíticos, Livro I. Campinas:

Instituto de Filosofia e Ciências Humanas, Coleção "Clássicos da

Filosofia: Cadernos de Tradução" v. 7.

ANGIONI, L. 2006. Introdução à teoria da predicação em Aristóteles.

Campinas: Editora da Unicamp.

ANGIONI, L. 2007. O conhecimento Científico no Livro I dos Segundos Analíticos de Aristóteles. Revista de Filosofia Antiga (http://www. revistas.usp.br/filosofiaantiga/article/view/42469), v. I, n. 2, 2007.

ANGIONI, L. 2009.In what sense there is no science of corruptible things: an analysis of Posterior Analytics I 8. Cadernos de História e Filosofia da Ciência v. 19, n. 1, pp. 61-87. 
ANGIONI, L. 2010. Prioridade e Substância na Metafísica de Aristóteles. Dois Pontos 7: 3, p. 75-106.

ANGIONI, L. 2012. Os Seis Requisitos das Premissas da Demonstração Científica em Aristóteles. Segundos Analíticos I 2, Manuscrito v. 35, n. 1, p. $7-60$.

ANGIONI, L. 2013a. Conhecimento e opinião em Aristóteles. Segundos Analíticos I-33, forthcoming.

ANGIONI, L. 2013b. Definition and essence in Aristotle's Metaphysics vii 7 , forthcoming in Ancient Philosophy.

BARNES, J. 1981. Proof and the Syllogism. In: Berti, E.(ed.). Aristotle on Science. Padova: Antenore, p.17-59.

BARNES, J. 1993. Posterior Analytics. 2 ed. Oxford: Oxford University Press.

BURNYEAT, M.F. 1981. Aristotle on Understanding Knowledge. In: Berti, E.(ed.). Aristotle on Science.Padova:Antenore, p.97-140.

FINE, Gail. 2010a. Aristotle's Two Worlds: Knowledge and Belief in Posterior Analytics I.33. Proceedings of the Aristotelian Society, CX, 3, p. 323-346.

FINE, Gail. 2010b. Aristotle on Knowledge In: Fronterotta, F. (ed.). La Scienza e le cause a partire dalla Metafisica di Aristotele, Napoli: Bibliopolis, p. 121-156.

GERSON, Lloyd. 2009. Ancient Epistemology. Cambridge University Press.

HARARI, Orna. 2010. Knowledge and Demonstration: Aristotle's Posterior Analytics. Dordrecht: Kluwer.

HINTIKKA, Jaakko. 1972. On the ingredients of an Aristotelian science. Nous 6, p. 55-69.

KIEFER, Thomas. 2007. Aristotle's Theory of Knowledge. London/NY: Continuum. 
KOSLICKI, Kathrin. 2012. Essence, necessity and explanation. In: Tahko, T. (ed.). Contemporary Aristotelian Metaphysics. Cambridge: Cambridge University Press, p. 187-206.

KOSMAN, L.A. 1973. Explanation, Understanding and Insight in Aristotle's Posterior Analytics. In: Lee, Mourelatos, Rorty (edd.). Exegesis and Argument.Van Gorcum: Assen.

LEAR, Jonathan. 1980. Aristotle and Logical Theory. Cambridge:

Cambridge University Press.

LLOYD, A. C. 1981. Necessity and Essence in the Posterior Analytics. In: Berti, E. (ed.). Aristotle on Science Padova:Antenore, pp. 157-171. MATTHEN, Mohan. 1981. The Structure of Aristotelian Science. In: Matthen, M. (ed.), Aristotle Today: Essays on Aristotle's ideal of science. Edmonton: Academic Printing \& Publishing, p. 1-23.

McKIRAHAN, Richard. 1992. Principles and Proofs. Aristotle's Theory of Demonstrative Science. Princeton: Princeton University Press.

MIGNUCCI, Mario. 2007. Aristotele - Analitici Secondi. Roma-Bari: Ed. Laterza.

MURE, G. (trans.) 1925. Posterior Analytics, In: ROSS, D. (ed.). The Complete Works of Aristotle Translated into English, Oxford: Clarendon Press.

PELLEGRIN, P. 2005. Aristote - Seconds Analytiques. Paris: GF Flammarion.

PERAMATZIS, Michail. [draft]. Aristotle on Knowledge and Belief: Posterior Analytics A-33. (unpublished draft).

PHILOPONUS. 1909. In Aristotelis Analytica Posteriora Commentaria. Commentaria in Aristotelem Graeca v. XIII, Ed. Maximiliam Wallies, Berlin: Walter de Gruyter, 1909.

PORCHAT, O. 2000. Ciência e Dialética em Aristóteles. São Paulo: Ed. UNESP. 
ROSS, W. D. 1949. Aristotle's Prior and Posterior Analytics. Oxford: Oxford University Press.

TAYLOR. C. C. W. 1990. Aristotle's epistemology. In: S. Everson (ed). Epistemology. Cambridge University Press, p.116-142. 